\title{
USERS' PERCEPTION AND EVALUATION OF CAMPUS ECO-OPEN SPACES AT THE UNIVERSITY OF LAGOS, AKOKA CAMPUS, NIGERIA
}

\author{
NNEZI UDUMA-OLUGU, OLAWALE IBRAHIM OLASUPO \& JOHN ADEKUNLE ADESINA \\ Department of Architecture, University of Lagos, Nigeria
}

\begin{abstract}
The design and conception of a university campus is usually done in a manner to create an attractive, conducive atmosphere which is serene as well as beautiful to encourage a right environment for study. University of Lagos prides itself as the University First Choice and the nation's pride in Nigeria. The university's unique location besides a lagoon and in an urban setting, gives it the opportunity to exploit the benefits of water tourism and other forms of nature in form of recreation within the eco-open spaces on campus. The aim of the study was to examine people's perception of the green infrastructure provided, the serenity of the existing eco-open spaces which students always visit due to their biophilic aspects, subsequently evaluate the facilities provided and how they are received by the users. A survey of eighty (80) copies of photo-questionnaires distributed to respondents, which consisted of students, visitors and staff who were met at the various venues. Out of these, 77 were returned correctly filled and used for analysis. Conclusions were reached and recommendations made, in line with the results of the study.
\end{abstract}

Keywords: campus eco-open spaces, green infrastructure, landscape perception, landscape urbanism, recreation.

\section{INTRODUCTION}

In studying people's perception of the open spaces in various parts of the University of Lagos, it is necessary to define open space - open space is defined in the Town and Country Planning Act 1990 as land laid out as a public garden, or used for the purposes of public recreation, or land which is a disused burial ground. However, in this study, open space should be taken to mean all open space of public value, including not just land, but also areas of water such as rivers, canals, lakes and reservoirs which offer important opportunities for sport and recreation and can also act as a visual amenity.

The following typology illustrates the broad range of open spaces that may be of public value:

- Parks and gardens - including urban parks, country parks and formal gardens;

- Natural and semi-natural urban greenspaces - including woodlands, urban forestry, scrub, grasslands;

- Green corridors - including river and canal banks, cycleway, and rights of way;

- Outdoor sports facilities (with natural or artificial surfaces and either publicly or privately owned);

- Amenity greenspace (most commonly, but not exclusively in housing areas) including informal recreation spaces, greenspaces in and around housing, domestic gardens and village greens;

- Provision for children and teenagers - including play areas, skateboard parks, outdoor basketball hoops, and other more informal area (e.g. "hanging out" areas, teenage shelters);

- Allotments, community gardens, and city (urban) farms; 
- Cemeteries and churchyards;

- Accessible countryside in urban fringe areas; and

- Civic spaces, including civic and market squares, and other hard surfaced areas designed for pedestrians.

An open space network should encourage more active lifestyles by offering a variety of safe and attractive spaces that are well distributed throughout a neighbourhood and are accessible and cater to the sporting and recreational needs of the community [1]. Preferably public open space should attempt to cater for multiple users.

Biophilic open spaces as it relates to the university, are elements and qualities of the physical environment that connect people to the physical, psychological, and cognitive benefits derived from direct, indirect or symbolic experiences with nature. These natural attributes are preferable in part because they literally bring buildings to life physically through the use of design strategies and materials, and symbolically through an understanding of deeply rooted affiliations, associations and meanings. Biophilic open spaces design attributes include: dynamic natural light, natural ventilation, access to open and/or moving water, frequent opportunities for spontaneous interaction with nature, sensory connections to nature, complexity and order, mystery, prospect and refuge, fundamental natural forms, and local natural materials [2], [3].

Immersion in natural environments is even more beneficial. Physically, patients recover faster when exposed to images and elements of the natural environment both before and after surgery [4]. Researchers have consistently found that people with access to nearby natural settings are healthier than other individuals [5]. Encouraging and enabling connections is highly beneficial both emotionally and physically.

Perhaps more importantly, this detachment between humanity and our natural environment has led to apathy towards the effects of our actions on the biosphere which, creates greater environmental problems by isolating the community from our natural surroundings, we place our mental and physical health at risk [4]. Nature is beneficial to all regardless of age, race, gender, or ethnicity. Contact with nature has been found to promote recovery from stress and disorder. Certain plants and habitats have been associated with stress-relieving, curative effects, calming, healing effects on the sick, and disposure of patients to therapeutic gardens can produce symptoms relieving [4], [6]. Much of the foregoing research discussed the effect of nature on recovering patients. This study concentrates on the effect of nature and eco-open spaces on its users within a university setting. The aim of the study is therefore to:

1. Study the open spaces on the campus.

2. Determine the provisions that are available for users.

3. Investigate the perceptions of the users of the eco-open spaces provided on the campus.

\section{LITERATURE REVIEW}

\subsection{Eco-open spaces perceptions}

There are five essential principles of biophilia which can be applied to architecture either for the purpose of guiding the development of the design as well as evaluating its merits: affiliation and affinity, wellness, bio centric ethics, prospect, and refuge and homeostasis [2], [4]. These principles relate to the elements of building design, some more strongly than others. The biophilic principles are all strongly connected, just as there is truly no clear line 
between each of the building elements, each affects and interacts with the others, working together to form a cohesive whole.

\subsubsection{Affinity and affiliation}

There are four basic levels of affiliation for developing biophilic affinity. These four levels of affiliation are contact, association, views and proxy. While each level of affiliation can develop biophilic affinity, the more personal and immediate the affiliation, the stronger the psychological and emotional connections will be. Affinity consists primarily of emotional connections which cause humans to attach value to some item. Contact is the most immediate level of affiliation which occurs when we associate with elements to the point where they enter our personal space, including physical contact. Such affiliation is more powerful due to the intensity of sensation caused by the physical closeness of item which involves senses of touch and smell.

\subsubsection{Wellness}

People who have had more exposure to the environment are healthier in a broad range of ways. They are less likely to have mental illnesses, develop attention deficit disorders, suffer from excess stress, which causes additional health issues and are less likely to be obese or overweight, which causes even more health problems.

\subsubsection{Bio centric ethics}

Ethics are the theoretical or philosophical concepts behind morality. Environmental ethics begins essentially with the issue of instrumental value versus intrinsic value done to the environment. Or, on the other hand, is there an intrinsic value to the natural environment outside of what it means to us as humans?

\subsubsection{Prospect and refuge}

Human beings naturally seek high ground and shelter for protection and in order to get a better view of our surroundings. The comfort and relaxation we feel looking out over a vista is an aspect of a human survival trait, not simply a matter of aesthetics. The concept of prospect and refuge is the most directly applicable biophilic principle in architectural terms.

\subsubsection{Homeostasis}

Homeostasis is defined as 'a relatively stable state of equilibrium or a tendency toward such a state between the different but interdependent elements or groups of elements of an organism, population, or group'. The natural world exists naturally in a homeostatic, largely self-corrective state. Removing elements from that natural cycle or ignoring the cycle entirely can throw the entire system out of balance and makes the return to homeostasis much harder.

\subsection{Therapeutic effect of natural surroundings}

A large body of research has confirmed the hypothesis that, contact with nature can lead to increased mental health and psychological well-being [2], [4], [7]. Many studies have found that contact with actual rather than representational nature has the most consistent and powerful therapeutic effects. To determine the benefits of experience with nature, it is essential to determine the types of contact we have with the natural environment. The contact is not limited to only a natural environment or landscape but could include the simple notion of nature. According to Kellert [2], there are three types of contact we can have with nature: direct, indirect and symbolic. 
Direct contact involves immediate experience with natural processes such as hiking through a forest, swimming in a stream or mountain climbing. Direct contact usually involves a person immediately within a natural environment.

Indirect contact involves some kind of human intervention or control such as mowing a lawn, viewing an aquarium or gardening.

Symbolic contact does not require any physical contact with natural processes or organic life forms. It involves a symbolic or metaphoric encounter such as depictions of landscapes in art or photographs or the use of organic patterns and forms in either decoration or architecture.

According to environmental psychologists contact with the natural environment can have a psychologically restorative effect on people. Restorative environments whether they be in the context of nature or the built environment, incorporate elements that function therapeutically by reducing cognitive fatigue and alleviating stress. These environments provide opportunities for rest, recovery, contemplation, and isolation [4]. The positive effects from contact with nature or natural views have proven to be greatest when people are experiencing high levels of stress or are confined to situations like hospitals, prisons and work environments.

In this case frequent direct, indirect or symbolic contact with nature continue to have a positive physical and psychological effect on human well-being. Kellert [2], identifies four benefits of contact with nature in built environment; Nature tends to correlate with physical activity which obviously promotes health. Nature activities often imply socialization in form of walking in group, sitting in a park with friends, building social network. Nature offers temporary escape from every day routine and demands. To what extent interaction with nature can have an appreciable impact on the mind. These benefits of contact with nature can be explained further in three ways [5], The air may be healthier in that it contains less air pollutants and more humidity. Plants may emit fragrance that humans find pleasant or react to in various ways. Visual experience of plants makes difference in that nature appears to have qualities useful for stress relief, mental restoration, and improve mood simply by consciously or unconsciously pleasing to the eye. Humankind does not merely have a preference for natural landscapes, they are also important to our physical and mental health. Numerous studies have shown that regular exposure to natural elements is highly beneficial to mental health, particularly stress reduction [8].

\subsection{Biophilic design approach in the planning and designing of the open spaces}

The adoption of biophilic design approach and framework in the planning process will lead to mental benefit, physical benefit and social benefit for the users; mental benefit in terms of stress and violence reduction, improved concentration. Physical benefit in the areas of enhancing health, rapid healing, and improved campus environmental condition. Social benefit which is crime reduction, student productivity, economic stimulation, better academic studies and greener open spaces. It is necessary to consider users' perception of the open spaces within the campus as it relates to the aforementioned human psychological, emotional and the physical factors that determine how the spaces are used.

The various attributes of a biophilic open space design cannot be over emphasized as they are key to the connectivity and usability of the various open spaces and the presence of nature improves health and well-being of its users. It reduces heat, improves air quality, reduces noise, stimulates fauna and flora, cleanses water runoff for the environment. Both the value and aesthetics of the open spaces improves the green rating of the environment. A biophilic eco-open space protects the users and the facilities from direct exposure to harsh elements. 


\subsection{The people's psychological perception of the campus open spaces}

The human perceptions of the open spaces within the campus as it relates to the human psychological, emotional and the physical factors that must be given considerations. The foremost importance of an eco-open space having the biophilic attributes is therapy. Petelot [9], argued that the interactions with green spaces are essential for mental wellbeing "our green spaces are essential for mental wellbeing, our garden allows us to work the earth, to watch things grow" people often times scratch the soil, breathe in the scent of plants and flowers let off steam and meet other people.

The physical form of a university's open spaces provides safety, security, accessibility, social interaction and campus entertainment. Based on the social lifestyle of the students, hyper-density leads to a decline in the social relations and make people avoid contact when the open space is hyper-dense, but the university's context shows the opposite meaning the open spaces never experience hyper-density which could affect the student psyche. Nevertheless, the eco-open spaces provide psychological comfort, healthy environment, recreation and ecological naturalness. Steptoe and Feldman [10] assure that hyper-density environment leads to poor health.

\section{METHODOLOGY}

The first stage focused on identifying the eco-open spaces in the Campus. Secondary data from topographical maps, 2017 satellite images, previous soil and hydrological studies and field work were used to document existing vegetation and open space network of the University. A key component of the technical analysis was the on-site quality assessment, which considered site condition, provision of facilities and level of maintenance. Sites were assessed using a methodology that scored them on a one to four (poor, fair, good or excellent) basis. Generic criteria, (such as safety, accessibility and how welcoming the site is, applied to all sites and specific criteria such as biodiversity, horticultural excellence and play value) were used for particular sites.

The final stage involved the data collection through a survey of one of the sites. This stage included the use of structured interviews of students and various users' opinion to document perceptions of the university's eco-open spaces. Data was collected through purposeful sampling; a primary survey of eighty (80) questionnaires distributed to respondents, which consisted of visitors, staff and students of the University of Lagos. Out of the eighty copies of questionnaire distributed only seventy-seven (77) was successfully filled and returned to the researchers. Based on this, the presentation and analysis were done; using frequency distribution tables to presents the respondents' demographic data. These were analyzed using Statistical Package for Social Sciences (IBM Statistics SPSS 20.0).

\section{RESULTS}

\section{1 presentation of respondents' demographic characteristics}

This section presents the respondents' demographic data using frequency distribution tables.

Table 1 reveals that 52 or $67.5 \%$ respondents were between the age 16-30 years of age, 24 or $31.2 \%$ respondents are within the age bracket of $31-45$ years, while 1 or $1.3 \%$ respondents are within the age brackets of 46-60 years. This table's results are not surprising since it shows that mostly young people that are between 16-30 years of age responded to the questionnaire - this is the expected age bracket of most students in the university. 
Table 1: Percentage distribution of respondents' by age. (Source: Field Survey, 2016.)

\begin{tabular}{|cc|c|c|c|c|}
\hline & Frequency & Percent & Valid percent & $\begin{array}{c}\text { Cumulative } \\
\text { percent }\end{array}$ \\
\hline \multirow{4}{*}{ Valid } & $16-30$ & 52 & 67.5 & 67.5 & 67.5 \\
& $31-45$ & 24 & 31.2 & 31.2 & 98.7 \\
& $46-60$ & 1 & 1.3 & 1.3 & 100.0 \\
& Total & 77 & 100.0 & 100.0 & \\
\hline
\end{tabular}

Table 2: Percentage distribution of respondents' by gender. (Source: Field Survey, 2016.)

\begin{tabular}{|cc|c|c|c|c|}
\hline & Frequency & Percent & Valid percent & $\begin{array}{c}\text { Cumulative } \\
\text { percent }\end{array}$ \\
\hline \multirow{3}{*}{ Valid } & Male & 27 & 35.1 & 35.1 & 35.1 \\
& Female & 50 & 64.9 & 64.9 & 100.0 \\
& Total & 77 & 100.0 & 100.0 & \\
\hline
\end{tabular}

Table 3: Percentage distribution of respondents by highest educational qualification. (Source: Field Survey, 2016.)

\begin{tabular}{|l|c|c|c|c|}
\hline & Frequency & Percent & Valid percent & $\begin{array}{c}\text { Cumulative } \\
\text { percent }\end{array}$ \\
\hline Primary school & 7 & 9.1 & 9.1 & 9.1 \\
Secondary school & 28 & 36.4 & 36.4 & 45.5 \\
Technical school/ & 4 & 5.2 & 5.2 & 50.6 \\
Valid & 23 & 29.9 & 29.9 & 80.5 \\
BSClytechnic & 15 & 19.5 & 19.5 & 100.0 \\
MSc/BA & 77 & 100.0 & 100.0 & \\
Total & & & \\
\hline
\end{tabular}

Table 2 shows the distribution of the respondents by sex, $35.1 \%$ of the respondents were male, while the remaining $64.9 \%$ of them were female. This indicates that the majority of respondents that attended to the questionnaire were female.

Table 3 indicates that 7 or $9.1 \%$ respondents were primary school holders, while 28 or $36.4 \%$ respondents were secondary school holders, 4 or $5.2 \%$ respondents have technical school or polytechnic certificates, 23 or $29.9 \%$ respondents and 15 or $19.5 \%$ respondents were $\mathrm{MSc} / \mathrm{PhD}$ holders. This table shows that majority of respondents were mostly educated which is to be expected within a university environment.

Table 4 shows that $24.7 \%$ respondents are visitors to the university, $49.4 \%$ respondents are undergraduate students of the university of Lagos, $20.8 \%$ respondents are post graduate students of the university while $5.2 \%$ respondents are staff of the school. This table shows that majority of respondents are undergraduate students. 
Table 4: How would you describe yourself? (Source: Field Survey, 2016.)

\begin{tabular}{|c|c|c|c|c|c|}
\hline & & Frequency & Percent & Valid percent & $\begin{array}{c}\text { Cumulative } \\
\text { percent }\end{array}$ \\
\hline \multirow{5}{*}{ Valid } & Visitor & 19 & 24.7 & 24.7 & 24.7 \\
\hline & Undergraduate students & 38 & 49.4 & 49.4 & 74.0 \\
\hline & Post graduate students & 16 & 20.8 & 20.8 & 94.8 \\
\hline & Staff & 4 & 5.2 & 5.2 & 100.0 \\
\hline & Total & 77 & 100.0 & 100.0 & \\
\hline
\end{tabular}

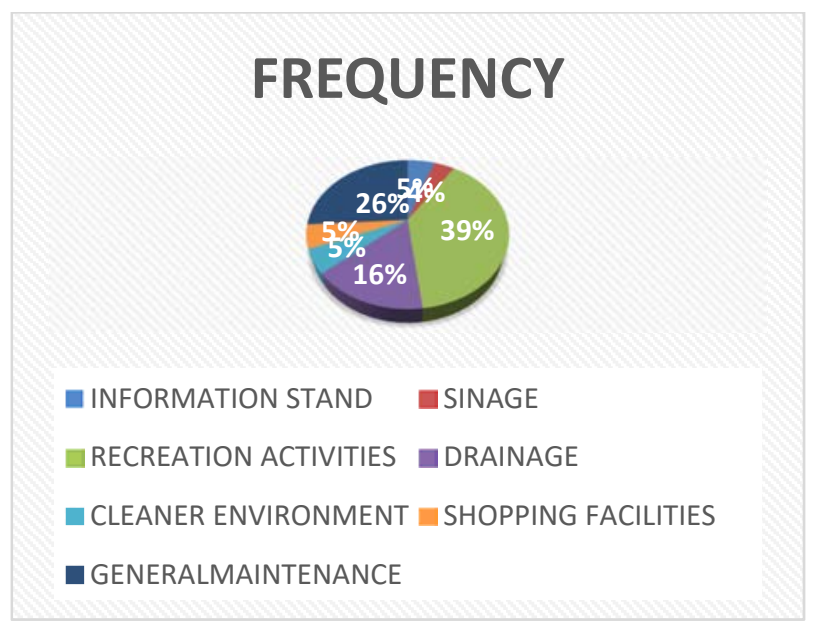

Figure 1: What key facilities are missing in the open spaces that you will like provided/improved? (Source: Field Survey, 2016.)

\subsection{Respondents perceptions}

Fig. 1 shows that $5.2 \%$ respondents said they will like the university to provide or improve on information stands, 3.9\% respondents said signage, 39\% respondents said recreational activities, $15.6 \%$ respondents said drainage, $5.2 \%$ respondents said cleaner environment $5.2 \%$ respondents said shopping facilities, $26 \%$ respondents said general maintenance This figure shows that majority of respondents wants more recreational facilities to be created by the university.

Table 5 shows that $13 \%$ respondents said they consider students hostel of the university as the best landscape, $14.3 \%$ respondents chose the staff housing provided by the university, $22.1 \%$ respondents chose the academic areas of the university, $15.6 \%$ respondents chose the recreational areas of the university, $19.5 \%$ respondents chose the circulations zones of the university (Roads, Pathways, car/bus parks) and 10.4\% respondents chose the landmarks (water tank, senate building and entrance gates). This table shows that majority of respondents considers the academic areas of the university as the best landscape of the university, while the recreational areas only ranked third best. 
Table 5: Where would you consider the best landscape open space in the UNILAG campus? (Source: Field Survey, 2016.)

\begin{tabular}{|ll|c|c|c|c|}
\hline & Frequency & Percent & Valid percent & $\begin{array}{c}\text { Cumulative } \\
\text { percent }\end{array}$ \\
\hline \multirow{6}{*}{ Valid } & Students hostels & 10 & 13.0 & 13.7 & 13.7 \\
& Staff housing & 11 & 14.3 & 15.1 & 28.8 \\
& Academic areas & 17 & 22.1 & 23.3 & 52.1 \\
& Recreational areas & 12 & 15.6 & 16.4 & 68.5 \\
& Circulation zones & 15 & 19.5 & 20.5 & 89.0 \\
& Landmarks & 8 & 10.4 & 11.0 & 100.0 \\
Missing & Total & 73 & 94.8 & 100.0 & \\
Total & System & 4 & 5.2 & & \\
\hline
\end{tabular}

Table 6: What would you consider the worst landscape open space in the UNILAG campus? (Source: Field Survey, 2016.)

\begin{tabular}{|c|c|c|c|c|c|}
\hline & & Frequency & Percent & Valid percent & $\begin{array}{c}\text { Cumulative } \\
\text { percent }\end{array}$ \\
\hline \multirow{6}{*}{ Valid } & Students hostels & 31 & 40.3 & 40.3 & 40.3 \\
\hline & Staff housing & 12 & 15.6 & 15.6 & 55.8 \\
\hline & Academic areas & 10 & 13.0 & 13.0 & 68.8 \\
\hline & Recreational areas & 20 & 26.0 & 26.0 & 94.8 \\
\hline & Circulation zones & 4 & 5.2 & 5.2 & 100.0 \\
\hline & Total & 77 & 100.0 & 100.0 & \\
\hline
\end{tabular}

Table 6 shows that $40.3 \%$ respondents said they consider students hostel of the university as the worst landscape, $15.6 \%$ respondents chose the staff housing provided by the university, $13 \%$ respondents chose the academic areas of the university, and $26 \%$ respondents chose the recreational areas of the university, and 5.2\% respondents chose the circulations zones of the university (roads, pathways, car/bus parks). This table shows that majority of respondents consider the students hostel of the university as the worst landscape of the university, followed by the recreational spaces. This is informative as the respondents are indicating that the recreational spaces still need a lot of work to make them acceptable.

Table 7 shows that $26 \%$ respondents said the open space in the university should be reconstructed, $24.7 \%$ respondents said general maintenance, $22.1 \%$ respondents said more security should be provided, $5.2 \%$ respondents said more activities, $13 \%$ respondents said greenery. This table shows that majority of respondents said the open spaces should be reconstructed for better.

Fig. 2 shows that $35.1 \%$ respondents said they find the vegetation in the university of Lagos most interesting, $28.6 \%$ respondents chose the sculptures, $15.6 \%$ respondents chose the pathways, $11.7 \%$ respondents chose the park/street furniture's, $3.9 \%$ respondents chose the lightings. This figure shows that majority of respondents find the vegetation in the university more interesting than any other things. 
Table 7: In what ways can the open spaces on campus be improved with regards to the landscape? (Source: Field Survey, 2016.)

\begin{tabular}{|ll|c|c|c|c|}
\hline & Frequency & Percent & Valid percent & $\begin{array}{c}\text { Cumulative } \\
\text { percent }\end{array}$ \\
\hline \multirow{5}{*}{ Valid } & Reconstruction & 20 & 26.0 & 28.6 & 28.6 \\
& General maintenance & 19 & 24.7 & 27.1 & 55.7 \\
& Security & 17 & 22.1 & 24.3 & 80.0 \\
& More activities & 4 & 5.2 & 5.7 & 85.7 \\
& Greenery & 10 & 13.0 & 14.3 & 100.0 \\
Missing & Total & 70 & 90.9 & 100.0 & \\
Total & System & 7 & 9.1 & & \\
\hline
\end{tabular}

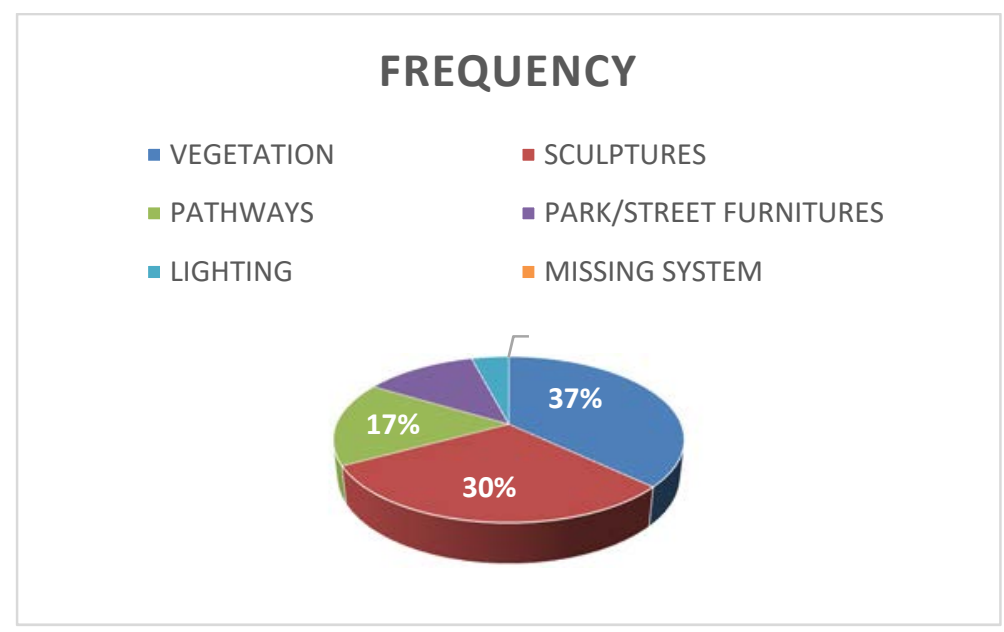

Figure 2: What elements do you find most interesting on campus? (Source: Field Survey, 2016.)

Fig. 3 shows that 5.2\% respondents said they perceive the open space in the University of Lagos as excellent, $19.5 \%$ respondents said it is very good, $49.4 \%$ respondents said it is good, and $11.7 \%$ respondents said it is bad. This figure shows that majority of respondents perceive the university of Lagos open space as good.

\section{CONCLUSION AND RECOMMENDATIONS.}

The result of the study shows that the students, visitors and staff of the University of Lagos open spaces generally perceive the spaces as average, indicating that work needs to be done to make them more desirous. The campus' vegetation was perceived as most interesting in the landscape, while a majority of the respondents were of the opinion that the open spaces require attention to restructure them; this was closely followed by those who responded that a lack of general maintenance of the open spaces was a problem. The research found that people's main concern was about quality and that issues associated with poor maintenance 


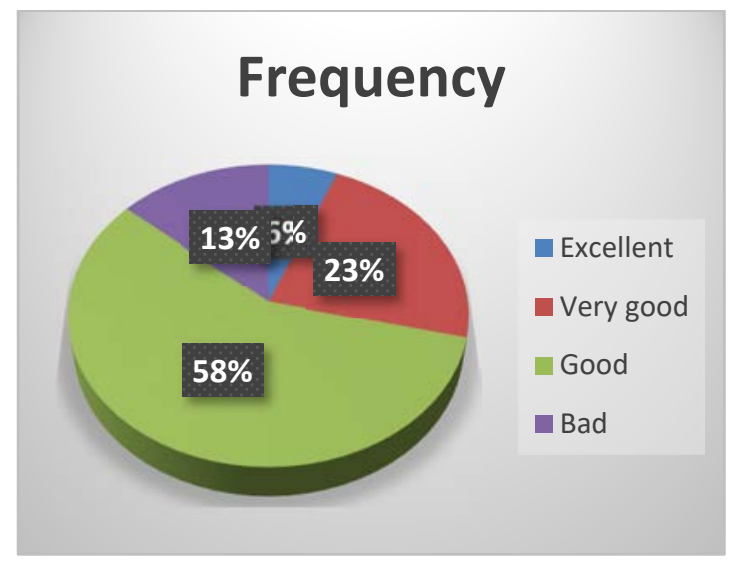

Figure 3: How do you perceive open space in the university of Lagos generally? (Source: Field Survey, 2016.)

were the main barriers to using green spaces. The student's hostels' open spaces were considered as having the worst landscape while the open spaces around the academic areas were perceived as the best by the respondents. There was a request for improvement and provision of more recreational spaces on campus.

The study has tried to bridge the distinct university's landscape psychological perceptions and the biophilic philosophical approaches. Drawing upon the literatures studied, the study also used the knowledge of theory and tested the validity of the analysis for design elements as it relates to users' attitudes and behavioral patterns in the open spaces. The various attributes of a biophilic open space design were certainly are key to the connectivity and usability of the various open spaces and the presence of nature as seen from the results. The methodology used in this study using the University of Lagos as a case study, was a combination of observation and interview which were undertaken in the local campus open spaces. Our findings have resulted in establishing a connection between landscape perception of the campus and the usage of the entire open spaces by the users.

The evidence base provided by this study is expected to enable University of Lagos in better planning of its open spaces and ensuring that new development contributes to the creation of a high-quality network of green spaces across the university for a more biophilic impact on its users. The University of Lagos open spaces need to better meet the psychological comfort of the students, staff and visitors through the use of available spaces to experience plants and trees in a more biophilic manner.

\section{REFERENCES}

[1] Auckland Council Public Safety and Nuisance Bylaw, Local Government Act 2002, the Local Government (Auckland Council) Act 2009 and the Health, Auckland Regional Council Parks Bylaw. www.aucklandcouncil.govt.nz/.

[2] Kellert, S.R., Nature and Its Symbols Keller-2005. The Art Book, Wiley, 2005.

[3] Taylor, B., Introducing the journal for the study of religion, nature and culture. www.religionandnature.com/JSRNC(1-1).

[4] Dillon, J. \& Jorde, D., Science Education Research and Practice in Europe, Springer, 2012. 
[5] Grinde, B. \& Patil, G., Sustainable Landscape Planning: The Reconnection Agenda. https://books.google.com.ng/books?isbn=184971262X, 2009.

[6] Bender, B., Contested Landscapes: Movement, Exile and Place. www.bloomsbury.com, 2001.

[7] Yudelson, J., The Green Building Revolution. www.jstor.org/stable/pdf/44105048, 2008.

[8] Kahn, P., Experiencing Nature: Affective, Cognitive, and Evaluative Development. www.researchgate.net, 1997.

[9] Petelot, M., Human Benefit of Green Spaces. http://extension.udel.edu/factsheets /human-benefits-of-green-spaces/University of DelawareBulletin\#137, 2008.

[10] Steptoe and Feldman, Neighborhood problems as sources of chronic stress. www.psychwiki.com/dms/other/Steptoe\%202001.pd. University College London. (C) 2001 by The Society of Behavioral Medicine, 2001. 